\title{
Lazer para idosos que residem em instituições de longa permanência
}

\section{Leisure for elderly people residing in long permanent institutions}

\author{
Tatiane Martins dos Santos' $\bullet$ Vinicius de Lima Lovadini ${ }^{\bullet}$ Amanda Kubo Leite ${ }^{3}$ Evelise Pires Cogo Simão $^{4}$
}

\begin{abstract}
RESUMO
Introdução: $O$ envelhecimento é um processo que envolve perda das atividades funcionais e propensão ao adoecimento. Entende-se que as vivências e práticas do cotidiano, estejam associadas à percepção de qualidade de vida, nas quais as atividades de lazer são frutos de escolhas assumindo a função de descanso, entretenimento pessoal e social. Objetivo: Identificar o tipo de atividade de lazer ofertada em uma instituição de longa permanência para idosos e a adesão de acordo com o nível de dependência. Métodos:Tratou-se de uma pesquisa quantitativa, transversal e descritiva. Resultados: Participaram da pesquisa 14 profissionais da equipe assistencial. Verificamos que 100\% dos idosos independentes aderem aos exercícios físicos, frequência a igreja e bate papo como atividades de lazer; 92,86\% dos idosos parcialmente dependentes optam pela prática de assistir televisão (TV) e bate papo; 100\% idosos dependentes aderem à prática de assistir TV. Constatamos que $92,86 \%$ das atividades de lazer são ofertadas por meio de serviço voluntariado e por servidores da própria instituição. Conclusão: Houve diversidade de atividades de lazer ofertadas, ainda que idosos possuam determinado grau de dependência para desenvolvê-las, sendo sua prática considerada importante pela equipe, em que a adesão está estreitamente relacionada a aspectos como concepções individuais de lazer e circunstância de saúde.

Palavras chaves:Atividades de lazer; assistência a idosos; Instituição de Longa Permanência para Idosos.
\end{abstract}

\begin{abstract}
ABSTACT
Introduction: Aging is a process that involves loss of functional activities and a propensity to fall ill. It is understood that everyday experiences and practices are associated with the perception of quality of life, in which leisure activities are the result of choices taking on the function of rest, personal and social entertainment. Objective:To identify the type of leisure activity offered in a long-term care facility for the elderly and adherence according to the level of dependency. Methods: It was a quantitative, transversal and descriptive research. Results: 14 professionals from the assistance team participated in the research. We found that $100 \%$ of independent elderly people adhere to physical exercise, attending church and chatting as leisure activities; $92.86 \%$ of partially dependent elderly people choose to watch television (TV) and chat; $100 \%$ dependent elderly people adhere to the practice of watching TV.We found that $92.86 \%$ of leisure activities are offered through voluntary service and by employees of the institution itself. Conclusion:There was a diversity of leisure activities offered, even though the elderly have a certain degree of dependence to develop them, their practice being considered important by the team, in which adherence is closely related to aspects such as individual conceptions of leisure and health circumstances.
\end{abstract}

Keywords: Leisure activities; assistance to the elderly; Long-Term Institution for the Elderly.

2 Mestre em Ciência Animal pela Faculdade de Medicina Veterinária de Araçatuba da Universidade Estadual Paulista Júlio de Mesquita Filho (FMVA-UNESP).Doutorando em Enfermagem pelo programa Interunidades Doutoramento em Enfermagem da Escola de Enfermagem de Ribeirão Preto da Universidade de São Paulo (EERP-USP). 3 Enfermeira graduada pela Universidade Paulista - UNIP.

4 Graduada em Enfermagem pelo Centro Universitário Católico Salesiano Auxilium (UNISALESIANO),Araçatuba. Doutora em Enfermagem pela Faculdade de Medicina de Botucatu da Universidade Estadual Paulista Júlio de Mesquita Filho (FMB-UNESP), Botucatu. 


\section{INTRODUÇÃO}

A demografia brasileira tem sofrido grandes mudanças nas últimas décadas, especialmente relacionada à inversão da pirâmide etária, colocando os idosos em maior número. Este aumento no público de idosos é devido ao aumento da expectativa de vida dos seres humanos associado com a demanda crescente na qualidade de vida (1). No decorrer dos tempos, novas tecnologias vão surgindo e paralelamente mudando os cenários anteriores, a exemplo são os avanços na área da saúde, que cada vez mais permitem novos tratamentos para patologias, meIhorando o prognóstico de vida do paciente (2).

Frequentemente na velhice, as disfunções de saúde causadas por patologias múltiplas são intensificadas pela solidão e pobreza, e a falta de companhia no idoso está diretamente associada às mudanças que atuam no interior das famílias. Com o aumento da população idosa, torna-se imprescindível, que a comunidade se conscientize desse conjunto de problemas e que de maneira rigorosa, as autoridades obtenham alternativas que direcionem a equidade na distribuição dos serviços e facilidades com essa determinada população. A questão social do idoso tem como finalidade amenizar a dura realidade que espera aqueles que conseguem perpetuar-se até idades mais avançadas. Depois de inúmeros esforços realizados para prorrogar a vida humana, seria lastimável não oferecer condições de conforto e satisfação ${ }^{(3)}$.

$O$ ato de cuidar vai muito adiante do atendimento das necessidades básicas de cada indivíduo. Cuidar é uma atitude que inclui o autocuidado, autoestima, autovalorização. Em geral, o cuidado dos idosos é realizado por um conjunto de base informal, que envolve família, amigos, vizinhos e, na maioria das vezes, é prestado voluntariamente e sem quaisquer remunerações. Mas, as famílias não possuem nenhum sistema de apoio do Estado, pois o sistema de saúde não está apto para atender às demandas dos idosos nem de seus familiares e cuidadores. Consequentemente, muitas famílias escoIhem institucionalizar seu idoso, procurando a Instituição de Longa Permanência para Idosos (ILPI), como um caminho acessível ${ }^{(4)}$.

Entretanto, não é característico da cultura brasileira institucionalizar seus idosos. Quase sempre é complicado e de difícil aceitação tanto para os idosos quanto para os demais entender as causas que levam as famílias a institucionalizá-los.Além disso, as ILPI eram, antigamente, conhecidas como asilos onde havia pouco acolhimento. Portanto, o cuidado nessas instituições está intimamente ligado a tomada de decisão em virtude de precisar de cuidados a longo prazo. As possibilidades de escolhas dos idosos são limitadas e por vez, inexistentes, devido à incapacidade vivida por eles que reduz o sentimento de autoconfiança e autonomia individual, transformando-os em dependentes para executar as atividades corriqueiras que exigem sustentação do próprio corpo ${ }^{(5)}$.

O enfermeiro é um dos colaboradores inseridos no quadro da multidisciplinaridade da ILPI e, consequentemente necessita estar presente nela. Cabe ao enfermeiro liderar e direcionar trabalhadores da equipe de enfermagem, sendo eles de nível médio ou técnico. Contudo esta realidade ainda não está presente na maioria das ILPIs. $O$ enfermeiro que deseja atuar em ILPI deve obter conhecimento sobre o processo de envelhecimento para: definir ações que possam servir integralmente as necessidades expressas e não expressas do idoso residente, buscando manter os princípios de autonomia e independência; capacitar a equipe de enfermagem a fim de qualificá-los a executar as ações do cuidado à pessoa idosa com sensibilidade, segurança, discernimento e compromisso ${ }^{(6)}$.

Entende-se que as vivências e práticas da vida cotidiana, principalmente as referentes ao lazer, estejam associadas à percepção de qualidade de vida dos idosos e sejam primordiais para a melhoria das relações sociais dos mesmos. As atividades de lazer são frutos de escoIhas pessoais para a procura do bem-estar, livres de obrigações, assumindo assim função de descanso, entretenimento e/ou de desenvolvimento pessoal e social. Logo, o lazer pode ser compreendido como um segmento complexo da vida social que determina relações da arte do diálogo, os deveres e as obrigações. Ainda, reproduz uma influência da cultura vivenciada através de manifestações culturais em um período conquistado pelo ser e favorecido para a demonstração do lúdico ${ }^{(7)}$.

Essas atividades de lazer podem ser distribuídas de acordo com o interesse central que excita o indivíduo a buscá-las, sendo elas: artísticas, manuais, físicas, racionais, sociais, turísticas e virtuais. Frente às diversas possibilidades de práticas culturais no lazer, torna-se imediato a ampliação do conhecimento sobre o lazer para os idosos (7).

Os idosos geralmente apresentam algumas dificuldades que permeiam o engajamento em atividades, tais como: medo de queda ou lesões graves, sensação de exaustão, morbidades, limitação física, dor, falta de acompanhamento ou de tempo para exercitar-se ${ }^{(8)}$.

São inúmeros os benefícios físicos e psicossociais que resultam da prática regular de qualquer atividade de lazer. Entre elas, estão: o ganho da força muscular, a melhora do condicionamento cardiorrespiratório, a diminuição de gordura, o aumento da densidade óssea, humor e autoestima melhorada, diminuição da ansiedade e da depressão. Esses benéficos envolvem o campo físico-funcional e mental dos indivíduos, mas refletem também na dimensão social, melhorando o desempenho funcional, mantendo e proporcionando a independência e a autonomia daqueles que atingem idades mais avançadas ${ }^{\left({ }^{(9)}\right.}$. 
É essencial sempre destacar a importância das atividades lúdicas como um método de possibilitar melhorias na qualidade de vida dos idosos institucionalizados e como forma de consolidar a autonomia de cada indivíduo. Estipular relações entre os idosos é indispensável para uma boa estadia na instituição e para conservação da saúde mental, visto que com a criação de vínculos o idoso não se sentirá só, podendo então, desempenhar ou fortificar relações com os outros idosos da instituição. Quanto maior a presença de interação entre eles aumentará os benefícios adquiridos e estes colaboram para a melhora da qualidade de vida ${ }^{(10)}$.

A relação entre o envelhecimento e o lazer é fundamental para a busca de bem-estar físico e mental, posto isto as atividades prazerosas proporcionadas aos idosos tendem a desenvolver momentos de distração e inspiração de forma positiva desencadeando conforto para saúde (1I).

Considerando que é essencial a participação dos idosos frente às atividades de lazer ${ }^{(6)}$, foram elaboradas as seguintes hipóteses a serem investigadas: Quais são os tipos de atividades de lazer ofertadas em uma instituição de longa permanência para idosos? Qual é a adesão dos idosos de acordo com seu nível de dependência?

O objetivo desta pesquisa foi identificar 0 tipo de atividade de lazer ofertada em uma instituição de longa permanência para idosos e verificar a adesão de acordo com o nível de dependência.

\section{MÉTODOS}

O presente estudo tratou-se de um estudo de natureza quantitativa, transversal e descritiva, a qual visou identificar quais atividades de lazer são oferecidas aos idosos que residem em uma instituição de longa permanência e se eles aderem às mesmas. A Instituição de longa permanência em pauta localiza-se no município de Araçatuba - SP e a pesquisa foi desenvolvida após submissão e aprovação pelo Comitê de Ética em Pesquisa (CEP), via Plataforma Brasil, sob o ${ }^{\circ}$ do parecer: 3.55I.597.

A pesquisa foi realizada em uma instituição de longa permanência para idosos, situada no município de Araçatuba - SP, devidamente autorizada por meio da assinatura do Termo de Intenção de Pesquisa pelas partes envolvidas.

A amostra foi composta por 14 profissionais da equipe assistencial (equipe de enfermagem e cuidador), que atuam na referida instituição, em diferentes períodos de trabalho.

A coleta de dados se procedeu por meio do preenchimento de um formulário semiestruturado, elaborado para esta finalidade, composto por 10 questões de múltipla escolha, o qual abordou questões relativas à participação dos idosos nas atividades de lazer desenvolvidas pela instituição, identificando quais são estas atividades disponibilizadas. $O$ formulário de pesquisa foi autopreen- chido, em que o pesquisador auxiliou na disponibilização do instrumento impresso com orientações sobre seu preenchimento.

Foram incluídos no estudo profissionais da equipe assistencial à saúde, dentre eles enfermeiros, técnicos de enfermagem, auxiliares de enfermagem e cuidador de idosos, de ambos os sexos, que atuam na referida instituição e que estiveram presentes no momento da coleta de dados e aceitaram participar da pesquisa. Foram excluídos da pesquisa profissionais afastados de suas atividades laborais por férias ou licença de qualquer natureza, durante o período de coleta de dados.

A coleta de dados se procedeu após aprovação deste órgão. Todos os participantes desta pesquisa assinaram o Termo de Consentimento Livre e Esclarecido - TCLE emitido em duas vias de igual teor, uma destinada ao pesquisador e outra para o próprio participante da pesquisa.

Foram utilizados equipamentos básicos de informática, como computador com acesso à internet, impressora e cartuchos de tinta para impressão, papel e caneta. Para registro e organização dos dados foi utilizado o programa Microsoft Excel 2010.

Os resultados foram apresentados por meio de frequências simples, demonstrados por meio de tabelas e figuras.

A pesquisa apresentou riscos mínimos, já que a coleta de dados se deu a partir do preenchimento de questionário, aplicado junto à equipe assistencial vinculada à instituição. Nenhum método experimental foi adotado.

\section{RESULTADOS}

A coleta de dados foi realizada entre os dias seis a nove de setembro de 2019 , nos três turnos de trabalho da equipe de enfermagem ( 13 profissionais) e cuidador (um profissional) da instituição de longa permanência do estudo. Houve a necessidade da exclusão de um profissional da pesquisa, devido ao afastamento de suas atividades laborais por férias, durante o período de coleta de dados.

No que diz respeito à caracterização do perfil sociodemográfico dos participantes da pesquisa, conforme demonstrado na Tabela I, observamos que $64,29 \%$ eram do sexo feminino, $76,43 \%$ possuíam idade entre 36 e 45 anos e $50 \%$ se definiram de etnia/raça branca. Outra vertente pesquisada foi a da religião dos participantes, em que $50 \%$ se declararam evangélicos. Entretanto do total dos entrevistados, independente da religião declarada, $57,14 \%$ relataram não serem praticantes. Ao que se referia ao estado civil 7I,43\% alegaram estarem casados, $64,29 \%$ possuíam dependentes e $35,71 \%$ responderam ter ao menos dois filhos.

Analisando a formação profissional dos entrevistados, sua maioria $(85,71 \%)$ eram auxiliares ou técnicos de enfermagem e destes, pelo menos $50 \%$ possuíam em torno 
de seis a dez anos de formação. Com relação ao tempo de vínculo empregatício institucional, dos entrevistados $42,86 \%$ registraram estar vinculados a instituição de longa permanência há pelo menos de dois a cinco anos. Ao serem questionados sobre deterem outro vínculo empregatício, $78,57 \%$ dos entrevistados afirmaram positivamente e destes $64,29 \%$ assinalaram que tal vínculo era como auxiliar ou técnico de enfermagem.

Dentre as demais variáveis estudadas e analisadas, encontramos similaridades em quatro delas, das quais $100 \%$ dos entrevistados afirmaram os itens indagados, sendo eles: se a instituição dispunha de práticas de lazer aos seus internos, se o profissional da instituição considerava as atividades de lazer ofertadas importantes, se os idosos costumam aderir às atividades ofertadas pela instituição e por fim se os institucionalizados recebiam visitas externas. Também foi constatado que o público que realiza visita aos institucionalizados configurava-se do ciclo de amigos, o correspondente $92,86 \%$ das respostas, de acordo com a Tabela 2.

Em relação a especificação de quem ofertava as atividades de lazer aos idosos residentes, obtivemos 0 resultado de $92,86 \%$ serem por meio de serviço voluntariado/servidores da própria instituição e 7,I4\% era por meio de serviços terceirizados, conforme consta na Tabela 3.

TABELA 1 - Caracterização sociodemográfica dos profissionais da equipe de enfermagem e participantes da pesquisa. Araçatuba-SP, Brasil, 2019.

\begin{tabular}{|c|c|c|c|}
\hline Variável & Categoria & $\mathbf{N}$ & $\%$ \\
\hline & 26 a 35 anos & 2 & 14,3 \\
\hline \multirow[t]{2}{*}{ Idade } & 36 a 45 anos & 10 & 71,4 \\
\hline & Mais de 45 anos & 2 & 14,3 \\
\hline \multirow{3}{*}{ Sexo } & Masculino & 5 & 35,7 \\
\hline & Feminino & 9 & 64,3 \\
\hline & Branca & 7 & 50 \\
\hline \multirow[t]{4}{*}{ Raça } & Negro & 1 & 7,14 \\
\hline & Pardo & 5 & 35,72 \\
\hline & Indígena & 1 & 7,14 \\
\hline & Católico & 4 & 28,57 \\
\hline \multirow[t]{3}{*}{ Religião } & Evangélico & 7 & 50 \\
\hline & Testemunha de Jeová & 1 & 7,14 \\
\hline & Outros (espírita) & 2 & 14,29 \\
\hline \multirow[t]{3}{*}{ Praticantes } & Sim & 6 & 42,86 \\
\hline & Não & 8 & 57,14 \\
\hline & Solteiro & 1 & 7,14 \\
\hline \multirow[t]{2}{*}{ Estado civil } & Casado & 10 & 71,42 \\
\hline & Divorciado & 3 & 21,44 \\
\hline \multirow[t]{4}{*}{ Possui dependentes } & Sim & 9 & 64,28 \\
\hline & Não & 5 & 35,72 \\
\hline & Não se aplica & 5 & 35,71 \\
\hline & 1 filho & 3 & 21,44 \\
\hline \multirow[t]{3}{*}{ Quantos filhos } & 2 filhos & 5 & 35,71 \\
\hline & 3 filhos & 1 & 7,14 \\
\hline & Auxiliar/técnico de enfermagem & 12 & 85,72 \\
\hline \multirow[t]{2}{*}{ Formação } & Enfermeiro & 1 & 7,14 \\
\hline & Cuidador & 1 & 7,14 \\
\hline \multirow[t]{3}{*}{ Tempo de formação } & 6 a 10 anos & 7 & 50 \\
\hline & Maior de 10 anos & 7 & 50 \\
\hline & 2 a 5 anos & 6 & 42,86 \\
\hline \multirow[t]{2}{*}{ Tempo de trabalho na instituição } & 6 a 10 anos & 3 & 21,43 \\
\hline & Maior de 10 anos & 5 & 35,71 \\
\hline \multirow[t]{4}{*}{ Possui outro vínculo empregatício } & Sim & 11 & 78,57 \\
\hline & Não & 3 & 21,43 \\
\hline & Não se aplica & 3 & 21,43 \\
\hline & Auxiliar/técnico de enfermagem & 9 & 64,29 \\
\hline \multirow[t]{2}{*}{ Função exercida em outra instituição } & Vendedora & 1 & 7,14 \\
\hline & Autônomo & 1 & 7,14 \\
\hline
\end{tabular}

Fonte: Dados da pesquisa. 
TABELA 2 - Distribuição das pessoas que realizam visitas aos idosos residentes na instituição de longa permanência, segundo resposta dos profissionais da equipe de enfermagem e cuidador participantes da pesquisa. Araçatuba-SP, Brasil, 2019.

\begin{tabular}{|c|c|c|}
\hline Quem o visita & $N^{\circ}(14)$ & $100 \%$ \\
\hline Amigos & 13 & 92,86 \\
\hline Filho(a) & 12 & 85,71 \\
\hline Irmãos & 12 & 85,71 \\
\hline Cônjuge & 4 & 28,57 \\
\hline Voluntários & 6 & 42,86 \\
\hline Grupo de jovens & 2 & 14,29 \\
\hline Alunos de escolas & 1 & 7,14 \\
\hline Anônimos & 1 & 7,14 \\
\hline
\end{tabular}

TABELA 3 - Distribuição dos responsáveis por oferecer as práticas de lazer aos idosos residentes em uma instituição de longa permanência. Araçatuba-SP, Brasil 2019.

\begin{tabular}{l|c|c}
\hline Quem oferece as práticas de lazer aos idosos & $\mathbf{N}^{\circ}(\mathbf{1 4})$ & $\mathbf{1 0 0 \%}$ \\
\hline Voluntariado & 13 & 92,86 \\
\hline Servidores da própria instituição & 13 & 92,86 \\
\hline Serviço terceirizado & 1 & 7,14 \\
\hline
\end{tabular}

Fonte: Dados da pesquisa.

$\mathrm{Na}$ Figura I são apresentados os achados envolvendo a participação dos idosos no planejamento e organização das práticas de lazer desenvolvidas, em que $71,4 \%$ dos entrevistados responderam existir tal prática na instituição.

No momento em que os profissionais foram questionados acerca da existência de razões médicas que interferem no cumprimento das atividades de entretenimento, $50 \%$ dos entrevistados confirmou a existência deste fator (Tabela 4), sendo a incapacidade de locomoção constatada como a maior limitação para a realização das atividades propostas, o correspondente a $50 \%$, quesito descrito na Figura 2.

Ao analisarmos o nível de dependência dos idosos, atrelando este ao fator a adesão à prática de lazer verificou-se que $100 \%$ dos idosos independentes aderem aos exercícios físicos, frequência a igreja e bate papo em cada modalidade citada.Já a maioria os idosos parcialmente dependentes aderem a assistir TV e bate papo, o correspondente a $92,86 \%$ em cada item. Contudo a prática mais frequente entre os idosos dependentes foi o ato de assistir TV (I00\%). O detaIhamento destas análises encontra-se disposto na Tabela 5.

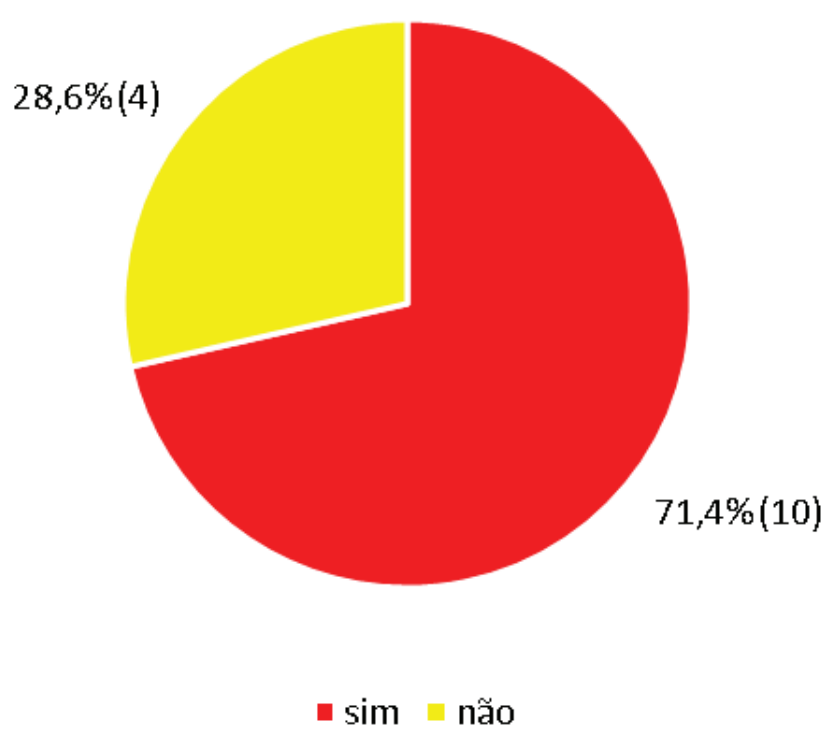

FIGURA 1 - Distribuição de acordo com a participação dos idosos no planejamento e organização das práticas de lazer em uma instituição de longa permanência. Araçatuba-SP, Brasil, 2019. 
TABELA 4 - Distribuição segundo a existência de razões médicas que limitam o cumprimento das práticas de lazer pelos idosos residentes em uma instituição de longa permanência. Araçatuba-SP, Brasil, 2019.

\begin{tabular}{l|c|c}
\hline Razões médicas & $\mathbf{N}^{\circ}$ & $\%$ \\
\hline Sim & 7 & 50 \\
\hline Não & 7 & 50 \\
\hline Total & $\mathbf{1 4}$ & $\mathbf{1 0 0}$ \\
\hline
\end{tabular}

Fonte: Dados da pesquisa.

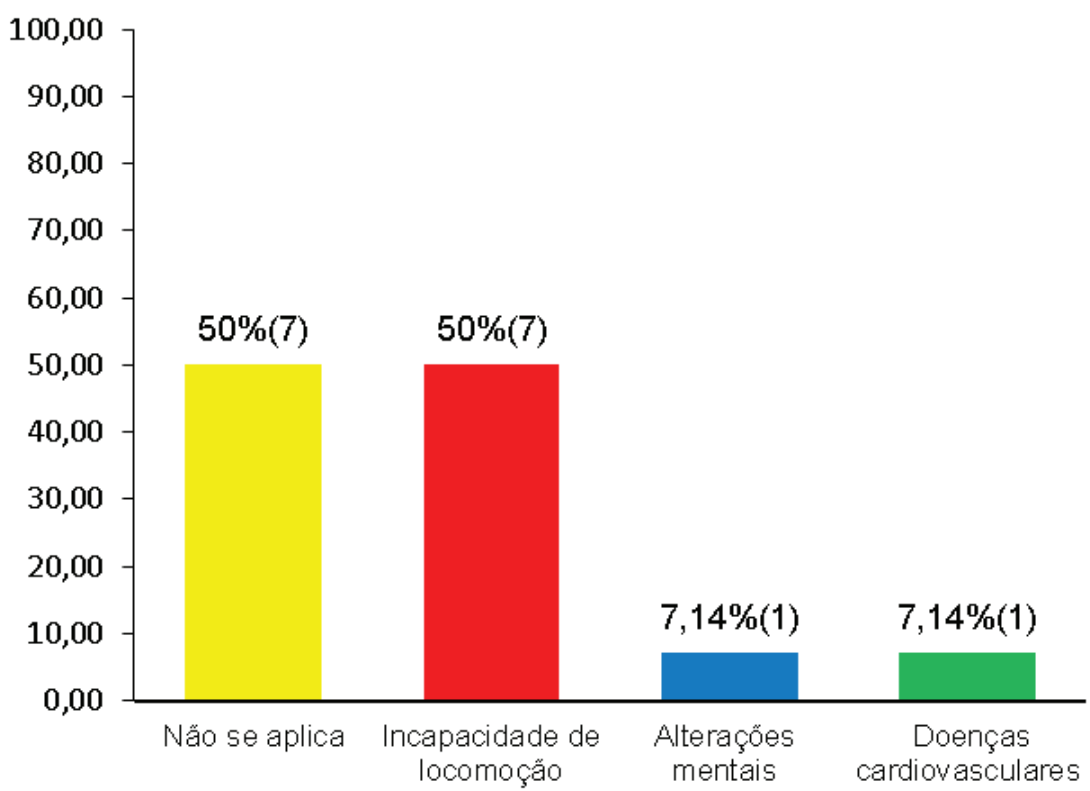

FIGURA 2. Distribuição segundo a classificação das razões médicas que limitam o cumprimento das práticas de lazer pelos idosos residentes. Araçatuba-SP, Brasil, 2019.

\begin{tabular}{|c|c|c|c|c|c|c|}
\hline \multirow[t]{2}{*}{ Atividades realizadas pelos idosos } & \multicolumn{2}{|c|}{ Independentes } & \multicolumn{2}{|c|}{$\begin{array}{l}\text { Parcialmente } \\
\text { Dependentes }\end{array}$} & \multicolumn{2}{|c|}{ Dependentes } \\
\hline & $\mathbf{N}^{\circ}$ & $\%$ & $\mathbf{N}^{\circ}$ & $\%$ & $\mathbf{N}^{\circ}$ & $\%$ \\
\hline Caminhadas & 9 & 64,29 & 0 & 0 & 0 & 0 \\
\hline Jogos (cartas, xadrez, dama) & 12 & 85,71 & 4 & 28,57 & 2 & 14,29 \\
\hline Exercícios físicos & 14 & 100 & 8 & 57,14 & 8 & 57,14 \\
\hline Frequentar a igreja & 14 & 100 & 10 & 71,43 & 4 & 28,57 \\
\hline Artesanato & 12 & 85,71 & 9 & 64,29 & 1 & 7,14 \\
\hline Assistir TV & 13 & 92,86 & 13 & 92,86 & 14 & 100 \\
\hline Música & 9 & 64,29 & 7 & 50 & 9 & 64,29 \\
\hline Bate-bapo & 14 & 100 & 13 & 92,86 & 10 & 71,43 \\
\hline Festas/dança/baile & 12 & 85,71 & 7 & 50 & 4 & 28,57 \\
\hline Leitura de livros, revistas e jornais & 8 & 57,14 & 3 & 21,43 & 2 & 14,29 \\
\hline Outros (fisioterapia) & 0 & 0 & 1 & 7,14 & 1 & 7,14 \\
\hline
\end{tabular}

Fonte: Dados da pesquisa. 


\section{DISCUSSÃO}

Constatamos com o desenvolvimento deste estudo que a grande maioria das pessoas que visitam os idosos institucionalizados, encontra-se no grupo de amigos, o que corrobora com estudo realizado em Natal-RN, que apontou que as pessoas que mais estavam presentes nas instituições de longa permanência durante os períodos de visita, não possuíam ligação consanguínea com os internos ${ }^{(12)}$.

Outro dado importante evidenciado por esta investigação foi o fato de que as atividades de lazer são ofertadas aos residentes da instituição de longa permanência por meio de serviço voluntariado, fato que corrobora com o estudo desenvolvido em Belo Horizonte, em que se constatou que os voluntários são os maiores responsáveis por fornecer diversas práticas de lazer aos idosos institucionalizados (13-14), sendo eles facilitadores de sensações positivas para contribuir com o bem estar dessas pessoas atendidas.

No que se refere à participação dos idosos no planejamento e organização das atividades de lazer, concluímos que os idosos dispõem de autonomia ao demostrarem suas preferências e interesses no ato de escolher a opção de entretenimento que mais os agradam, fato que refuta achado de estudo realizado em São BorjaRS, no qual o plano a ser seguido de atividades de lazer nas instituições que foram entrevistadas, era elaborado pela recreacionista anualmente e posteriormente apresentado aos residentes da instituição ${ }^{(14)}$, eximindo assim a liberdade de expressão dos idosos, frente ao que os mesmos desejam desenvolver.

A opção de escolha é de suma importância na vida dos residentes em instituições de longa permanência, fato evidenciado em resultados de investigação que enalteceu as opiniões dessas pessoas frente à opção de quais atividades eles desejam desenvolver, o que proporciona benefícios, como a satisfação e afasta o surgimento de pensamentos e emoções negativas nesse grupo estudado ${ }^{(15)}$.

O cumprimento de atividades físicas ou de lazer são essenciais para a melhora do condicionamento do indivíduo no processo de envelhecimento ${ }^{16}$. Portanto, tendo em consideração o que foi apontado por estudiosos, a incapacidade de locomoção como contraindicação médica para participar das atividades de lazer evidenciada por este estudo, refuta o que foi projetado no Vale do Paraíba em São Paulo, momento em que foi abordada a prática de atividades como um meio de favorecer a saúde do grupo de idosos, mesmo que esses indivíduos iniciem com um exercício de baixa intensidade, progredindo gradativamente, assim respeitando e trabalhando seu nível de dependência ${ }^{(16)}$.

Sobre o aspecto das atividades de lazer associados ao grau de dependência dos idosos residentes na instituição de longa permanência, podemos observar que independentemente do grau de dependência que o idoso apresente, existem atividades de lazer para todos os grupos citados, o que muda é a variação dentre a lista de atividades desenvolvidas ${ }^{(17)}$. A atividade física, por exemplo, é um meio saudável para lidar com as transformações do envelhecimento. Tornando-se assim um fator de preservação da capacidade funcional, posto que os exercícios físicos proporcionam a diminuição de dores articulares, acarretam melhora da força e flexibilidade, coordenação motora, entre outras, fato que enaltece o achado desta pesquisa, em que $100 \%$ dos idosos independentes aderem a prática de exercícios físicos.

Já com relação ao público parcialmente dependente e dependente, demonstrou-se destaque às atividades de assistir TV e bater papo, corroborando com o estudo desenvolvido no município de Natal, Rio Grande do Norte, no qual identificou que $90 \%$ das instituições de longa permanência possuem sala de TV, realidade que contribui significativamente para a socialização entre os residentes das ILPi's (18).

Acrescido ao exposto, é válido ressalvar se existe o cumprimento coerente com o que é preconizado na Política Nacional da Saúde do Idoso, que prevê qualidade de vida e segurança, dentre vários outros aspectos estabelecidos em legislação ${ }^{(8)}$.

As repercussões na vida dos idosos devem ser inquestionáveis, uma vez que a demanda de tempo na assistência ao cuidado exige atenção integral, consequentemente, sua vida pessoal não recebe as demandas necessárias para o bem estar do mesmo. Tais exigências acabam negligenciando o lazer, vida social, afeto e saúde, e em algumas situações até seus vínculos empregatícios, gerando problemas financeiros. Outro fato relevante é o de os idosos em sua maior parte não ter dependência financeira, deixando sua autonomia em segundo plano (19).

Com a educação continuada voltada para a saúde do idoso, conseguiríamos alcançar um maior quantitativo de profissionais de saúde para assegurarmos o cuidado e integridade exponencial para esta população, uma vez que os nossos dados identificaram e caracterizaram as fragilidades encontradas neste escopo.

\section{CONCLUSÃO}

Constatamos que a equipe assistencial considera importante o desenvolvimento das atividades de lazer ofertadas aos idosos.

As variáveis deste estudo evidenciaram a diversidade de atividades de lazer disponibilizadas para os idosos residentes nesta instituição de longa permanência, ainda que eles possuam determinado grau de dificuldade/dependência para desenvolvê-las, constatamos que as atividades fazem parte da rotina dos idosos e são de suma importância para a qualidade de vida dos mesmos. Neste sentido, fica salientado que a adesão efetiva às práticas de lazer está estreitamente relacionada a aspectos como concepções individuais de lazer e circunstância de saúde dos idosos. 


\section{REFERÊNCIAS}

I. Camacho ACLF, Coelho MJ. Políticas públicas para a saúde do idoso: revisão sistemática. Revista Brasileira de Enfermagem, vol. 63, 2010. Acesso em: 5 de abril de 2019. Disponível em: <https://www.redalyc.org/ pdf/2670/2670195940 I7.pdf>.

2. Mendes JLV, Silva SC, Silva GR, Santos NAR. Aumento da População Idosa no Brasil e o Envelhecimento nas Últimas Décadas: Uma Revisão da Literatura. REV. EDUC. MEIO AMB. SAÚ.V8 N I, 2018. Acesso em: 19 de abril de 2019. Disponível em: <file://C:/Users/User/Downloads//6547I-I-PB.pdf>.

3. Junior CSD, Costa CS. $O$ envelhecimento da população brasileira: uma análise de conteúdo das páginas da REBEP. Cedeplar/UFMG, 2006. Acesso em: 5 de abril de 2019. Disponível em: <file://C:/Users/User/Downloads/I52I4446- I-PB.pdf>.

4. Silva BT, Santos SSC. Cuidados aos idosos institucionalizados - opiniões do sujeito coletivo enfermeiro para 2026. Acta Paul Enferm, 2010. Acesso em: 6 de abril de 2019. Disponível em: <http://repositorio.furg.br/bitstream/handle/I/I300/Cuidados\%20aos\%20idosos\%20institucionalizados\%20\%20opini\%C3\%B5es\%20do\%20sujeito\%20coletivo\%20enfermeiro\%20para\%202026? sequence $=\mid>$.

5. Silva MV, Figueiredo MLF. Idosos institucionalizados: uma reflexão para o cuidado de longo prazo. Revista cofen, Enfermagem em Foco, 2012. Acesso em: 6 de abril de 2019. Disponível em: <http://revista.cofen.gov.br/index.php/enfermagem/article/view/215/|36>.

6. Santos SSC, Silva BT, Barlem ELD, Lopes RS. O papel do enfermeiro na instituição de longa permanência para idosos. Rev enferm UFPE, 2008. Acesso em: 6 de abril de 2019. Disponível em: <http://repositorio.furg.br/bitstream/handle/I/I537/PDF\%20n\%C2\%BA\%20|8.PDF?sequence=|>.

7. Santos PM, Marinho A, Mazo GZ, Hallal PC. Atividades no lazer e qualidade de vida de idosos de um programa de extensão universitária em Florianópolis (SC). Rev Bras Ativ Fis e Saúde, 2014.Acesso em: 27 de fev de 2019 e 5 de abril de 2019. Disponível em:<http://rbafs.org.br/RBAFS/article/ view/3254/pdf200>.

8. Zaitune MPA, Barros MBA, Cesar CLG, Carandina L, Goldbaum M,Alves MCGP. Fatores associados à prática de atividade física global e de lazer em idosos: Inquérito de Saúde no Estado de São Paulo (ISA-SP), Brasil. Cad. Saúde Pública, Rio de Janeiro, 2010. Acesso em: 6 de abril de 2019. Disponível em: <https://www.scielosp.org/pdf/csp/2010. $v 26 n 8 / 1606-1618 / p t>$.

9. Zaitune MPA, Barros MBA, César CLG, Carandina L, Goldbaum M. Fatores associados ao sedentarismo no lazer em idosos, Campinas, São Paulo, Brasil. Cad. Saúde Pública, Rio de Janeiro, 2007. Acesso em: 6 de abril de 2019. Disponível em: <https://www.scielosp.org/pdf/csp/2007. v23n6/I329-|338/pt>.
10. Fleurí ACP,Almeida ACS, Diniz AJ, Magalhães LAD, Ferreira LHC, Horta NC, Prata MTM, Moura RM. Atividades lúdicas com idosos institucionalizados. Rev. Enfermagem Vol. I6, 20I3.Acesso em: 5 de abril de 2019. Disponível em:<http:// periodicos.pucminas.br/index.php/enfermagemrevista/article/view/l 3018/10238>.

I I. Gonçalves HF, Joan EB. O Envolvimento de Idosos em Atividades Prazerosas: Revisão da Literatura sobre Instrumentos de Aferição. REV. BRAS. GERIATR. GERONTOL., RIO DE JANEIRO, 20I I; I4(3):579-590. Acesso em: $27 \mathrm{de} \mathrm{fev}$ de 2019. Disponível em <http://www.redalyc.org/articulo. oa? id=4038340430 I 6>.

12. Melo AD, Costa AVB, Dantas PBF, Maia AHS, Nunes VMA, Alchieri JC. Necessidades afetivas de idosos residentes em Instituições de Longa Permanência. J Health Sci Inst.;32(3):27I-6, 20I4. Acesso em: 17 de outubro de 2019. Disponível em: <https://www.unip.br/presencial/comunicacao/publicacoes/ics/edicoes/2014/03_jul-set/V32_ n3_20I4_p27la276.pdf>.

13. Moura GA. Experiências De Lazer De Idosos Independentes Institucionalizados. Belo Horizonte UNIVERSIDADE FEDERAL DE MINAS GERAIS, 20I2. Acesso em: 20 de outubro de 2019.Disponível em: < http://I50.164.124.4/eeffto/DATA/defesas/20150710192644.pdf>.

14. Dornelles RN. O acesso ao lazer para os idosos institucionalizados em municípios da fronteira oeste do Rio Grande do Sul. São Borja, 2017. Acesso em: 20 de outubro de 2019. Disponível em: < http://dspace.unipampa. edu.br/bitstream/riu/23 I 2///Rosimeri\%20Nardes\%20 Dornelles.pdf>.

15. Almeida MAG, Wagner V, Oliveira LP. Lazer nos centros de convivência dos municípios da região norte do Paraná. R. bras. Ci.e Mov;26(3):156-164, 2018. Acesso em: 21 de outubro de 2019. Disponível em: <https://portalrevistas.ucb.br/index.php/RBCM/article/ view/9631/pdf>.

16. Araújo CL, Faro ACM. La práctica de actividad física en personas mayores del Valle del Paraíba, São Paulo, Brasil. Enfermería Global, v. II, n. 4, 28 sep., 2012. Acesso em: 21 de outubro de 2019. Disponível em: <https://revistas.um.es/ eglobal/article/view/eglobal.II.4.|4785I>.

17. Nogueira WBS, Martins CD. O lazer na terceira idade e sua contribuição para uma melhor qualidade de vida: um estudo com idosos institucionalizados. Revista brasileira de enfermagem, Minas Gerais, 2017. Acesso em: 27 de outubro de 2019. Disponível em: < https://pdfs. semanticscholar.org/043c/d I b6f54fab77c3aa80478fee$819 b 0183 f 55 e . p d f>$.

18. Andrade LMB, Noronha K, Camargos MCS, Machado CJ. Perfis de integração social entre idosos institucionalizados não frágeis no município de Natal, Rio Grande do Norte. Cien Saude Colet [periódico na internet] (2018/ Set). Acesso em: 27 de outubro de 2019. Disponível 
em:<http://www.cienciaesaudecoletiva.com.br/artigos/ perfis-de-integracao-social-entre-idosos-institucionalizados-nao-frageis-no-municipio-de-natal-rio-grande-donorte/ $\mid 6956$ ? id $=\mid 6956>$.

19. ALBUQUERQUE, F. K. O. DE; FARIAS, A. P. DO E. C. DE; MONTENEGRO, C. DA S.; LIMA, N. K. F. DE; GERBASI, H.
C. L. M. Qualidade de vida em cuidadores de idosos: uma revisão integrativa. Revista Enfermagem Atual In Derme, v. 87, n. 25, 8 abr. 2019.

Recebido: 2020-03-23

Aceito: $2020-04-15$ 


\section{APÊNDICE I - Instrumento de coleta de dados}

Data da coleta de dados

Sexo:( ) Masculino ( ) Feminino

Idade: ( ) Menos de 25 anos ( ) 26 a 35 anos ( ) 36 a 45 anos ( ) Mais de 46 anos.

Cor/raça: ( ) Branco ( ) Negro ( ) Pardo ( )Amarelo ( ) Indígena

Religião: ( ) Católico ( ) Evangélico ( ) Testemunha de Jeová ( ) Outro Praticante:

( ) $\operatorname{Sim}($ )Não

Estado civil: ( ) Solteiro ( ) Casado ( ) Divorciado ( )Viúvo (a)

Possui dependentes: (filhos): ( )Não ( ) Sim (quantos

Formação:

( ) Auxiliar/Técnico de enfermagem ( ) Enfermeiro ( ) Cuidador

Tempo de formação:

( ) Menor de I ano( ) 2 a 5 anos( ) 6 a 10 anos( ) Maior de 10 anos

Trabalha a quanto tempo na instituição?

( ) Menos de I ano( ) 2 a 5 anos( ) 6 a 10 anos( ) Maior de 10 anos

Possuí outro emprego?

( ) $\operatorname{Sim}($ ) Não

Se sim, quais?

I - Esta instituição oferece práticas de lazer a seus residentes?
( ) SIM
( ) NÃO

2 - Você como profissional considera importantes estas atividades?
( ) SIM
( ) NÃO

3 - Os idosos aderem às atividades que a instituição lhes oferece?

( ) SIM

4 - Quem oferece estas práticas de lazer?

( ) NÃO
( ) Voluntariado
( ) Servidores da própria instituição
( ) Serviço terceirizado

5 - Os idosos participam no planejamento e organização das práticas de lazer?
( ) SIM
( ) NÃO

6 - Há razões médicas que limitam o cumprimento/participação em atividades de entretenimento pelos idosos?
( ) SIM
( ) NÃO

Se sim, especifique quais:
( ) Alterações mentais
( ) DPOC
( ) Incapacidade de locomoção
( ) Doenças cardiovasculares
( ) Outras. Especificar:

7 - Dentre a lista a seguir, quais atividades são realizadas pelo grupo de idosos independentes?
( ) Caminhadas
( ) Jogos(cartas, xadrez, dama)
( ) Exercícios físicos
( ) Frequentar a Igreja
( ) Artesanato
( ) Assistir TV
( ) Música
( ) Bate - Papo
( ) Festas/Dança/ Baile
( ) Leitura de livros, revistas e jornais
( ) Outras. Especificar:

8 - Dentre a lista a seguir, quais atividades são realizadas pelo grupo de idosos parcialmente dependentes?
( ) Caminhadas
( ) Jogos(cartas, xadrez, dama)
( ) Exercícios físicos
( ) Frequentar a Igreja
( ) Artesanato
( ) Assistir TV
( ) Música
( ) Bate - Papo
( ) Festas/Dança/ Baile
( ) Leitura de livros, revistas e jornais
( ) Outras. Especificar:

9 - Dentre a lista a seguir, quais atividades são realizadas pelo grupo de idosos dependentes?
( ) Caminhadas
( ) Jogos(cartas, xadrez, dama)
( ) Exercícios físicos
( ) Frequentar a Igreja
( ) Artesanato
( ) Assistir TV
( ) Música
( ) Bate - Papo
( ) Festas/ Dança/ Baile
( ) Leitura de livros, revistas e jornais
( ) Outras. Especificar: 
I0- Os idosos recebem visitas?

( ) SIM

Se sim, quem é a pessoa que o visita?
( ) Filho (a)

( ) Amigos

\section{( ) NÃO}
( ) Irmãos
( ) Cônjuge
( ) Outros. Especificar: 